\title{
Systemic exposure following intravitreal administration of therapeutic agents: an integrated pharmacokinetic approach. 1. THR-149
}

\author{
Marc Vanhove $^{1}$ (D) Bernard Noppen ${ }^{1} \cdot$ Jean-Marc Wagner ${ }^{2} \cdot$ Tine Van Bergen $^{1} \cdot$ Philippe Barbeaux $^{1} \cdot$ \\ Alan W. Stitt ${ }^{1,3}$
}

Received: 9 March 2021 / Accepted: 24 June 2021 / Published online: 23 July 2021

(c) The Author(s) 2021

\begin{abstract}
Intravitreal (IVT) injection of pharmacological agents is an established and widely used procedure for the treatment of many posterior segment of the eye diseases. IVT injections permit drugs to reach high concentrations in the retina whilst limiting systemic exposure. Beyond the risk of secondary complications such as intraocular infection, the potential of systemic adverse events cannot be neglected. Therefore, a detailed understanding of the rules governing systemic exposure following IVT drug administration remains a prerequisite for the evaluation and development of new pharmacological agents intended for eye delivery. We present here a novel mathematical model to describe and predict circulating drug levels following IVT in the rabbit eye, a species which is widely used for drug delivery, pharmacokinetic, and pharmacodynamic studies. The mathematical expression was derived from a pharmacokinetic model that assumes the existence of a compartment between the vitreous humor compartment itself and the systemic compartment. We show that the model accurately describes circulating levels of THR-149, a plasma kallikrein inhibitor in development for the treatment of diabetic macular edema. We hypothesize that the model based on the rabbit eye has broader relevance to the human eye and can be used to analyze systemic exposure of a variety of drugs delivered in the eye.
\end{abstract}

Keywords Intravitreal administration · Systemic exposure · Integrated pharmacokinetics

\section{Introduction}

In recent years, intravitreal (IVT) injection has become the preferred administration route of pharmacological agents for the treatment of the back of the eye diseases such as age-related macular degeneration and diabetic retinopathy. Despite being invasive and associated with a low risk of rhegmatogenous retinal detachment [1], the procedure offers the advantage to immediately achieve high, therapeutically-effective drug levels in the vitreous chamber [2].

This article is a companion paper of "https://doi.org/10.1007/ s10928-021-09774-9".

Marc Vanhove

marc.vanhove@oxurion.com

1 Oxurion N.V., Gaston Geenslaan 1, 3001 Leuven, Belgium

2 Haute École de la Province de Liège, Avenue Montesquieu 6, 4101 Seraing, Belgium

3 Centre for Experimental Medicine, Queen's University Belfast, Belfast, Northern Ireland, UK
Localized IVT administration also serves to considerably limit overall systemic exposure and therefore potential systemic adverse events [2]. This, however, doesn't imply that the risk of systemic complications doesn't exist for drugs administered intravitreally. Indeed, the systemic risk is well illustrated by the commonly used anti-VEGF agents which IVT administration is suspected to be associated with increased risk for ischemic cerebrovascular disease, thromboembolic events, non-ocular hemorrhagic events, nephrotoxicity, acute blood pressure elevations, serious systemic infections, gastrointestinal disorders, and even mortality. This is a low but consistent risk and limiting the bioavailability of systemic VEGF could be detrimental for vascular integrity, especially in patients with retinal disease who are also at risk for cardiovascular diseases [3-7].

Therefore, accurate understanding of systemic exposure following ocular delivery remains a critical step in the development of new ophthalmological drugs. Attempts to model e.g. drug circulating levels after IVT administration remain sporadic, though, and evaluation of systemic exposure, whether for preclinical models or human data, is 
oftentimes restricted to analyses based solely on descriptive parameters such as maximum observed concentration $\left(\mathrm{C}_{\max }\right)$, time to reach $\mathrm{C}_{\max }\left(\mathrm{t}_{\max }\right)$, and area under the curve (AUC) [8-15]. There are, however, noticeable exceptions. Le et al. [16] described an integrated ocular-systemic model for the anti-factor D antigen-binding fragment (Fab) lampalizumab in the cynomolgus monkey which takes into account target mediated drug disposition, target turnover, and drug distribution across ocular tissues and systemic circulation. Also, Luu et al. [17] reported a model for the anti-VEGF DARPin abicipar pegol that incorporates VEGF binding kinetics, VEGF expression levels, and VEGF turnover rates to describe ocular and systemic pharmacokinetic data in the rabbit. Buitrago et al. [18] used a three-compartment pharmacokinetic model to assess plasma levels after IVT injection of the chemotherapy drug topotecan in rabbits. Gadkar et al. [19] proposed a mathematical model for ocular (including vitreous, aqueous humor, and retina) and systemic pharmacokinetic analysis of a variety of antibodies and antibody fragments that can be generalized for all protein fragments derived from an antibody regardless of the presence of an $\mathrm{Fc}$ region. Finally, Xu et al. [20] and Zhang et al. [21] have shown that serum concentration of the anti-VEGF Fab fragment ranibizumab after IVT administration in patients with retinal vein occlusion, diabetic macular edema, and agerelated macular degeneration can be described by a onecompartment model with first-order absorption into and first-order elimination from the systemic circulation.

THR-149, a bicyclic peptide identified by a combination of phage-based selections and directed medicinal chemistry (see Teufel et al. [22] for a general description of the method), is a potent and specific inhibitor of plasma kallikrein currently being developed by Oxurion N.V. for the treatment of diabetic macular edema (source: www.clin icaltrials.gov). Here, we report the pharmacokinetic properties of THR-149 in the rabbit and propose a novel mathematical model to describe systemic exposure, in the form of circulating drug levels, following IVT administration. In the current study, the proposed mathematical expression was derived from a pharmacokinetic model that assumes the existence of an additional compartment between the vitreous humor (VH) compartment itself (i.e. the compartment where the drug is administered) and the systemic compartment. We also hypothesize, here and in our accompanying paper (Vanhove et al., this issue of $\mathbf{J}$. Pharmacokinet. Pharmacodyn. https://doi.org/10.1007/ s10928-021-09774-9), that this kind of model is generally applicable to describe plasma levels of drugs delivered into the eye.

\section{Methods}

\section{Animal studies}

Housing and all experimental procedures were conducted according to accepted best practice (EU Directive/AAALAC or similar) and approved by Institutional Animal Care and Research Advisory Committee of the KU Leuven according to the 2010/63/EU Directive. All animal procedures were also performed in accordance with the ARVO Statement for the Use of Animals in Ophthalmic and Vision Research.

\section{Nonlinear regression analyses}

Nonlinear regression analyses were performed using the GraphPad Prism software ver. 5.02 (GraphPad Software Inc., La Jolla, CA) applying, unless otherwise stated, equal weighting (i.e. performing minimization based on absolute distances squared). For the modelling of plasma levels following IVT administration with Eq. 13 (Fig. 5b), and in order to compute a unique value for the parameter $k_{2}$, the data set was analyzed "globally" i.e. considering that the data obtained for the different doses represent a unique set of data, and with $\mathrm{k}_{2}$ used as a "shared" parameter to employ the terminology used in GraphPad Prism (we refer the reader to the GraphPad Prism software ver. 5.02 user's manual for a description of how global fitting of such data sets can be performed). Precision on the fitted parameters was expressed as $95 \%$ confidence intervals $\left(\mathrm{CI}_{95 \%}\right)$.

\section{Intravitreal pharmacokinetics}

Male New-Zealand White (NZW) rabbits (10 weeks old, $1.7-2.0 \mathrm{~kg}$ ) received a single injection of $50 \mu \mathrm{L}$ of $2.5 \mathrm{mg} /$ $\mathrm{mL}$ THR-149 $(125 \mu \mathrm{g})$ in each eye. General anesthesia was induced by intramuscular injection of $50 \mathrm{mg} / \mathrm{mL}$ ketamin (Ketalar, Pfizer) and 2\% (v/v) sedative (Rompun, Bayer Health Care). Pupils were dilated with a drop of tropicamide (Tropicol, Théa Pharma). IVT injections were performed using $30 \mathrm{G}, 0.3 \mathrm{~mL}$ insulin syringes with halfunit $(50 \mu \mathrm{L})$ marks (BD Micro-Fine) under $4 \mathrm{mg} / \mathrm{mL}$ topical anesthesia (Unicain, Thea Pharma). The animals were sacrificed 1 h, 4 h, 8 h, 24 h, 48 h, 96 h, and 168 h after injection ( 3 animals per time point), the injected eyes were enucleated and the vitreous was collected. The vitreous samples from each eye were treated separately, homogenized mechanically, and clarified by centrifugation as previously described [23], then further clarified by $0.2 \mu \mathrm{m}$ filtration (Nanosep ${ }^{\circledR}$ MF with Bio-Inert ${ }^{\circledR}$ membrane, VWR, cat. 516-8554). THR-149 was quantified in the vitreous samples by HPLC. HPLC analyses were 
performed using an Acquity UPLC instrument (Waters). One volume of each sample was diluted into 1.5 volume of $8.33 \%(\mathrm{v} / \mathrm{v})$ acetonitrile, $0.17 \%(\mathrm{v} / \mathrm{v})$ trifluoroacetic acid (TFA), $0.067 \%(\mathrm{v} / \mathrm{v})$ Tween-20, and $6 \mu \mathrm{L}$ of the diluted samples were injected on a BEH300 C18 $1.7 \mu \mathrm{m}$, $2.1 \times 100 \mathrm{~mm}$ Acquity UPLC column (Waters, cat. 186003686) pre-equilibrated in $0.1 \%$ (v/v) TFA. Elution was performed by applying a 1-mL, 5-40\% (v/v) acetonitrile linear gradient in $0.1 \%$ (v/v) TFA and THR-149 was detected by following the absorbance at $215 \mathrm{~nm}$. The flow rate was $100 \mu \mathrm{L} / \mathrm{min}$ and the temperature of the column was maintained at $75^{\circ} \mathrm{C}$. The concentration of THR-149 in the samples was calculated by integration of the relevant peak and reference to a standard curve obtained by injection of a series of samples of known concentration.

Data (THR-149 concentration vs. time) were analyzed based on a mono-compartmental model (Eq. 1, where D is the dose, $\mathrm{V}_{\mathrm{D}, \mathrm{VH}}$ the vitreal volume of distribution, and $\mathrm{k}_{1}$ the first-order rate constant of vitreal drug elimination) applying a proportional weighting i.e. performing minimization based on relative distances squared. Half-life in the $\mathrm{VH}$ was calculated from Eq. 2 and vitreal clearance $\left(\mathrm{CL}_{\mathrm{VH}}\right)$ was obtained from Eq. 3.

$$
\begin{aligned}
& {[\mathrm{THR}-149]_{V H}=\frac{D}{V_{D, V H}} \cdot e^{-k_{1} \cdot t}} \\
& t_{1 / 2}=\frac{\ln (2)}{k_{1}} \\
& C L_{V H}=k_{1} \cdot V_{D, V H}
\end{aligned}
$$

\section{Intravenous pharmacokinetics}

NZW rabbits $(\mathrm{n}=8$, males and females, 12 weeks old, 1.7-2.0 kg, Charles River) received a single intravenous administration of THR-149 (5 mg/kg) via the marginal ear vein using a $26 \mathrm{G}$ needle (Becton Dickinson) under local anesthesia (10\% xylocaine spray). Blood was collected via the marginal ear vein in EDTA-coated sample tubes (Sarstedt, Multivette ${ }^{\circledR}$, MUL-E-600) connected to a $26 \mathrm{G}$ needle $30 \mathrm{~min}, 2 \mathrm{~h}$, and $4 \mathrm{~h}$ after THR-149 administration for the first four animals, and $1 \mathrm{~h}, 3 \mathrm{~h}$, and $6 \mathrm{~h}$ after THR149 administration for the remaining four animals. Plasma was prepared by centrifugation $(10 \mathrm{~min}$ at $1400 \times \mathrm{g})$ and THR-149 levels were determined by LC-MS using an Acquity UPLC coupled to a QDa instrument (Waters). Prior to analysis, plasma samples were diluted with 2 or 3 volumes of $0.1 \%(\mathrm{v} / \mathrm{v})$ formic acid in acetonitrile and centrifuged for $10 \mathrm{~min}$ at $13,000 \mathrm{rpm}$. The supernatants were further diluted in $0.1 \%(\mathrm{v} / \mathrm{v})$ formic acid in water and $6 \mu \mathrm{L}$ of the diluted samples were injected on a BEH C18 300A, $1.7 \mu \mathrm{m}, 2.1 \times 100 \mathrm{~mm}$ Acquity UPLC column (Waters, cat. 186003686) pre-equilibrated in $10 \%(\mathrm{v} / \mathrm{v})$ acetonitrile and $0.1 \%(\mathrm{v} / \mathrm{v})$ formic acid. The temperature of the column was maintained at $65^{\circ} \mathrm{C}$. Elution was performed by applying a $3-\mathrm{mL}, 10-44 \%(\mathrm{v} / \mathrm{v})$ acetonitrile linear gradient in $0.1 \%(\mathrm{v} / \mathrm{v})$ formic acid at a flow rate of $600 \mu \mathrm{L} / \mathrm{min}$. THR-149 was detected in positive polarity single ion recording mode via its $[\mathrm{M}+3 \mathrm{H}]^{3+}$ ion. The concentration of THR-149 in the samples was calculated by integration of the peak in the ion chromatogram and reference to a standard curve obtained by injection of a series of samples of known concentration (625-4.88 ng/ $\mathrm{mL})$.

Data (plasma concentration vs. time) were analyzed based on a mono-compartmental model using Eqs. 4, 5 and 6 (with $\mathrm{D}$ the dose, $\mathrm{V}_{\mathrm{D} \text {,syst }}$ the systemic volume of distribution, $\mathrm{k}_{3}$ the first-order rate constant of systemic drug elimination, and $\mathrm{CL}_{\text {syst }}$ the systemic clearance) applying a proportional weighting.

$$
\begin{aligned}
& {[\mathrm{THR}-149]_{\text {syst }}=\frac{D}{V_{D, s y s t}} \cdot e^{-k_{3} \cdot t}} \\
& t_{1 / 2}=\frac{\ln (2)}{k_{3}} \\
& C L_{\text {syst }}=k_{3} \cdot V_{D, s y s t}
\end{aligned}
$$

\section{Plasma levels following intravitreal administration}

THR-149 was solubilized at 2.5, 5.0, 7.5, 10, and $20 \mathrm{mg} /$ mL. Male NZW rabbits (14-16 weeks old, average weight $3.1 \mathrm{~kg}, \mathrm{CEGAF}$ ) received a single, 50- $\mu \mathrm{L}$ IVT administration of THR-149 in both eyes, thus representing a dose of $0.125 \mathrm{mg}, 0.25 \mathrm{mg}, 0.375 \mathrm{mg}, 0.5 \mathrm{mg}$ or $1 \mathrm{mg}$ per eye, depending on the concentration of the administered solution. The administration procedure was identical to the one described above except that $29 \mathrm{G}$ syringes were used. Blood samples were collected $0.5,1,4,8$, and $24 \mathrm{~h}$ after THR-149 administration via the marginal ear vein in EDTA-coated sample tubes (Sarstedt, Multivette $\AA$, MUL-E-600) connected to a $26 \mathrm{G}$ needle and plasma was prepared by centrifugation $(10 \mathrm{~min}$ at $1400 \times g)$. THR-149 concentration in plasma samples was assessed by LC-MS/MS at Charles River Discovery (Groningen, The Netherlands). Of each prepared sample, a $30-\mu \mathrm{L}$ aliquot was injected onto the HPLC column by an automated sample injector (SIL20-AC HT, Shimadzu, Japan). Chromatographic separation was performed on a reversed phase analytical column (Atlantis T3, $150 \times 2.1 \mathrm{~mm}, 3.0 \mu \mathrm{m}$, Waters, USA) held at a temperature of $30{ }^{\circ} \mathrm{C}$. Components were separated using a gradient of acetonitrile containing $0.1 \%(\mathrm{v} / \mathrm{v})$ formic acid in ultrapurified $\mathrm{H}_{2} \mathrm{O}$ containing $0.1 \%(\mathrm{v} / \mathrm{v})$ formic acid at a flow rate of $0.2 \mathrm{~mL} / \mathrm{min}$. The MS analyses were performed using an API $5000 \mathrm{MS} / \mathrm{MS}$ system equipped with a Turbo 
Ion Spray interface (both from Sciex, USA). The instrument was operated in multiple-reaction-monitoring mode. The acquisitions were performed in positive ionization mode with optimized settings for THR-149. Data were acquired and processed using the Analyst ${ }^{\mathrm{TM}}$ data system ( $\mathrm{v}$ 1.4.2, Sciex, USA).

Data (THR-149 concentration vs. time) were analyzed based on Eqs. 7 or 13 (see 'Results' section).

\section{Results}

\section{Intravitreal pharmacokinetics}

Pharmacokinetic data following administration of $125 \mu \mathrm{g}$ of THR-149 in the rabbit eye are shown in Fig. 1 and summarized in Table 1. THR-149 exhibited a relatively long residence time in the $\mathrm{VH}$ with a first-order rate constant of vitreal elimination $\left(\mathrm{k}_{1}\right)$ of $0.0195 \mathrm{~h}^{-1}$ corresponding to a half-life of $36 \mathrm{~h}$. The vitreal volume of distribution was slightly larger than the vitreous volume $(1.66 \mathrm{~mL}$ vs. $1.15 \mathrm{~mL})$ and vitreal clearance was $0.032 \mathrm{~mL} / \mathrm{h}$. Of note, there was no evidence of metabolic degradation of THR-149 in the vitreous (not shown).

\section{Intravenous pharmacokinetics}

The decrease in the circulating concentration of THR-149 following intravenous administration in rabbit $(5 \mathrm{mg} / \mathrm{kg})$ was best described by a single exponential (Fig. 2). Plasma concentration vs. time data were thus analyzed based on a mono-compartmental model (Eqs. 4, 5 and 6) leading to a first-order rate constant of systemic elimination $\left(\mathrm{k}_{3}\right)$ of $0.64 \mathrm{~h}^{-1}$ (corresponding to a half-life of $1.1 \mathrm{~h}$ ), a volume

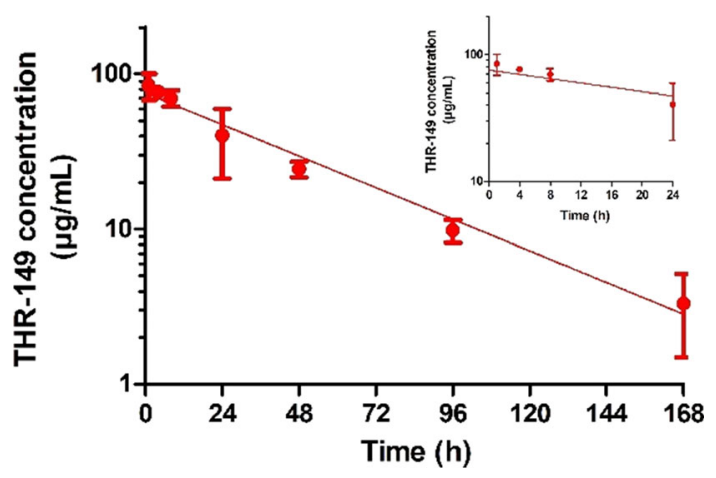

Fig. 1 Pharmacokinetics in the rabbit $\mathrm{VH}$ following intravitreal administration of $125 \mu \mathrm{g}$ of THR-149. Data are shown as mean \pm SD. The solid line represents the best fit given by Eq. 1. THR-149 exhibits a relatively long residence time in the $\mathrm{VH}$ with a rate constant of drug elimination $\left(\mathrm{k}_{1}\right)$ of $0.0195 \mathrm{~h}^{-1}$ corresponding to a half-life of $36 \mathrm{~h}$
Table 1 Pharmacokinetic parameters of THR-149 in rabbit

\begin{tabular}{ll}
\hline Parameter & \\
\hline Vitreous volume $(\mathrm{mL})$ & 1.15 \\
$\mathrm{k}_{1}\left(\mathrm{~h}^{-1}\right)$ & $0.0195[0.0177-0.0214]$ \\
Vitreal half-life $(\mathrm{h})$ & $36[32-39]$ \\
$\mathrm{V}_{\mathrm{D}, \mathrm{VH}}(\mathrm{mL})$ & $1.66[1.46-1.92]$ \\
$\mathrm{CL}_{\mathrm{VH}}(\mathrm{mL} / \mathrm{min})$ & $0.032[0.029-0.036]$ \\
$\mathrm{k}_{2}\left(\mathrm{~h}^{-1}\right)$ & $0.056[0.049-0.063]$ \\
$\mathrm{k}_{3}\left(\mathrm{~h}^{-1}\right)$ & $0.64[0.55-0.73]$ \\
$\mathrm{Systemic}$ half-life $(\mathrm{h})$ & $1.1[0.9-1.2]$ \\
$\mathrm{V}_{\mathrm{D}, \text { syst }}(\mathrm{L} / \mathrm{kg})$ & $0.51[0.40-0.73]$ \\
$\mathrm{CL}_{\text {syst }}(\mathrm{mL} / \mathrm{min} / \mathrm{kg})$ & $5.5[4.4-6.5]$ \\
\hline
\end{tabular}

The values of $k_{1}$ and $k_{3}$ were obtained from intravitreal pharmacokinetics (Fig. 1) and intravenous pharmacokinetics (Fig. 3), respectively. The value of $\mathrm{k}_{2}$ was calculated from plasma levels following IVT administration

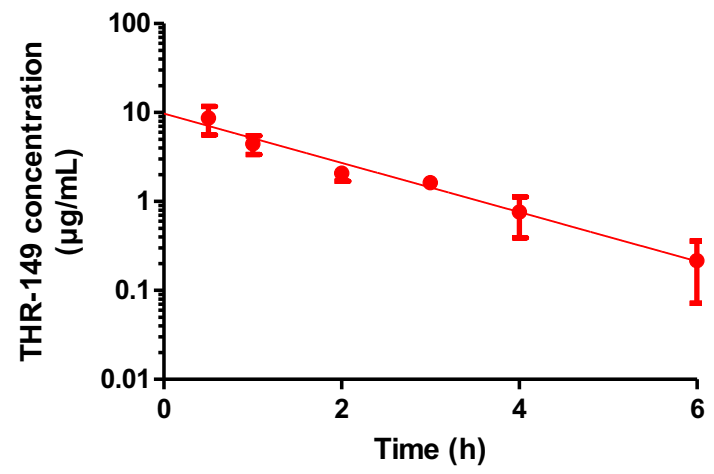

Fig. 2 Drug plasma levels following intravenous administration of $5 \mathrm{mg} / \mathrm{kg}$ of THR-149 in rabbits. Data are shown as mean \pm SD and were analyzed based on a mono-compartmental model. The solid line represents the best fit given by Eq. 4 . THR-149 is cleared quickly from the circulation with a rate constant of drug elimination $\left(\mathrm{k}_{3}\right)$ of $0.64 \mathrm{~h}^{-1}$ corresponding to a half-life of $1.1 \mathrm{~h}$

of distribution of $0.51 \mathrm{~L} / \mathrm{kg}$, and a clearance of $5.5 \mathrm{~mL} /$ $\mathrm{min} / \mathrm{kg}$ (Table 1). Together with a high metabolic stability in presence of liver microsomes which suggests a limited potential of hepatic clearance (not shown), these data are in agreement with renal clearance at glomerular filtration rate.

\section{Plasma levels following intravitreal administration}

Systemic exposure (i.e. plasma levels over time) following IVT administration of THR-149 in rabbit was measured for doses ranging from $0.125 \mathrm{mg}$ per eye to $1 \mathrm{mg}$ per eye (corresponding to total doses per animal ranging from 0.25 to $2 \mathrm{mg}$ since THR-149 was administered bilaterally—drug elimination from each eye was assumed to be identical and additive when modeling plasma exposure). These data are 


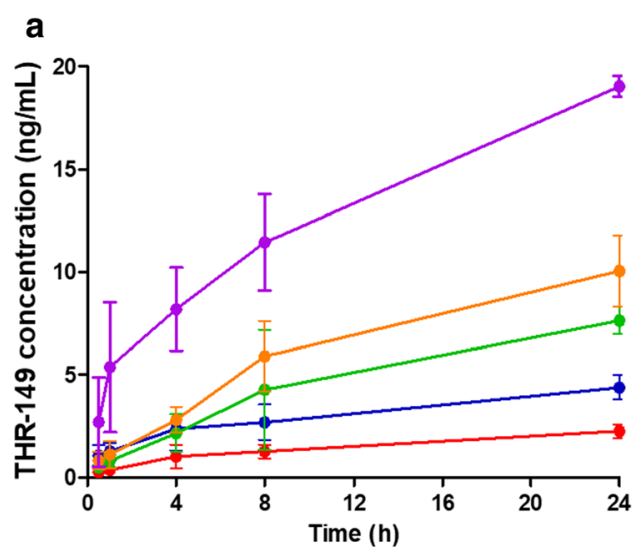

Fig. 3 Plasma levels (a) and systemic exposure expressed as area under the curve (AUC) between 0 and $24 \mathrm{~h}$ obtained by the trapezoidal method (b) following bilateral intravitreal administration

presented in Fig. 3a. Plasma levels increased steadily, the higher levels being observed at the latest time point $(24 \mathrm{~h})$ for all doses. Overall plasma levels were also directly proportional to actual dosing as shown from the perfect correlation between the area under the curve (AUC) measured between 0 and $24 \mathrm{~h}$ by the trapezoidal method and the dose (Fig. 3b).

$\mathrm{Xu}$ et al. and Zhang et al. [20, 21] have modelled circulating drug levels following IVT administration on the basis of a model with first-order absorption into and firstorder elimination from the systemic circulation, a model which, therefore, is essentially identical to the two-compartment pharmacokinetic model depicted in Fig. 4a. In this model, $\mathrm{k}_{1}$ represents the first-order rate constant for transfer of the drug from the vitreal compartment to the systemic compartment and $\mathrm{k}_{3}$ the first-order rate constant for systemic elimination. Although neither $\mathrm{Xu}$ et al. nor Zhang et al. present an analytical solution to their model, the variation of the drug concentration in each of these compartments as a function of time can be obtained by solving (i.e. integrating) the following system of linear differential equations (Eq. syst. 1), where A and B
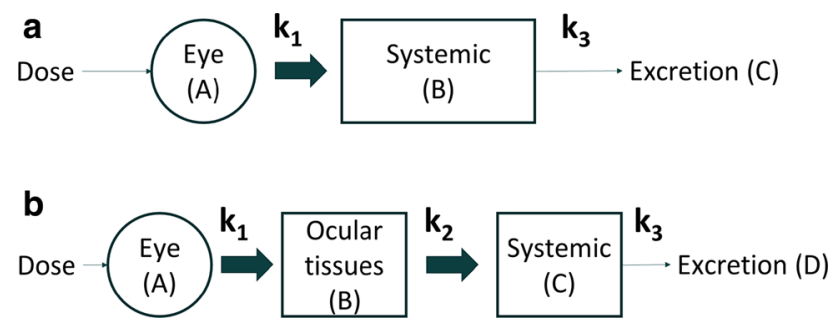

Fig. 4 Two-compartment (a) and three-compartment (b) pharmacokinetic models used to analyze drug circulating levels following intravitreal administration of THR-149 in rabbit

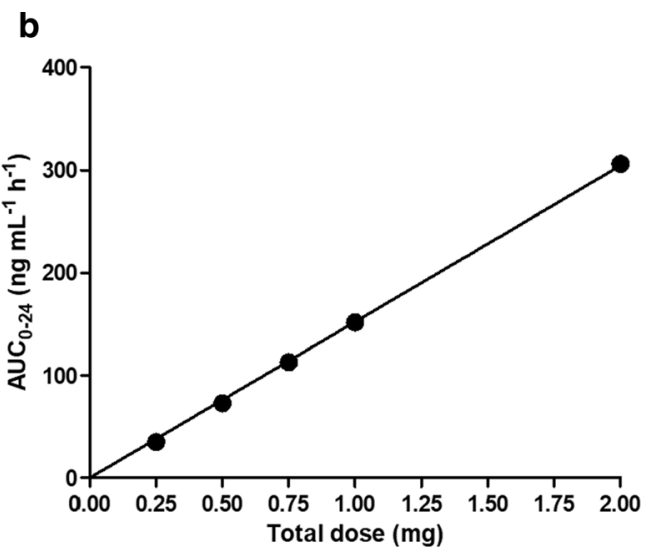

of THR-149 in rabbit. Data in a are shown as mean \pm SD. Doses ranged from 0.125 to $1 \mathrm{mg}$ per eye (corresponding to total doses per animal ranging from 0.25 to $2 \mathrm{mg}$ )

represent the $\mathrm{VH}$ and systemic compartments, respectively, and $\mathrm{C}$ the eliminated drug (Fig. 4a):

$d A / d t=-k_{1} \cdot A$

$d B / d t=k_{1} \cdot A-k_{3} \cdot B$

$d C / d t=k_{3} \cdot B$

The solution of such a system of linear differential equations is common knowledge. For the second compartment, representing systemic distribution, the solution is in the form of Eq. 7 where [THR-149] $]_{\text {syst }}$ represents the concentration of the drug in plasma at any point in time (see e.g. [24]):

$[\mathrm{THR}-149]_{\text {syst }}=\frac{D \cdot k_{1}}{V_{D, \text { syst }} \cdot\left(k_{1}-k_{3}\right)} \cdot\left(e^{-k_{3} \cdot t}-e^{-k_{1} \cdot t}\right)$

The rate constants $k_{1}$ and $k_{3}$ in Eq. 7 also appear in Eqs. 1 and 4, respectively, and therefore the value of all the parameters of Eq. 7 (namely $\mathrm{D}, \mathrm{V}_{\mathrm{D} \text {,syst }}, \mathrm{k}_{1}$, and $\mathrm{k}_{3}$ ) are known from either intravitreal or intravenous pharmacokinetics. Equation 7 should thus accurately predict drug circulating levels following IVT administration. Figure 5a shows, however, that this is not the case. Equation 7 indeed not only poorly describes actual drug levels in general, but it also predicts that the circulating concentration will reach a maximum value $\left(\mathrm{C}_{\max }\right)$ at $\sim 5.6 \mathrm{~h}$ whereas THR-149 levels are observed to increase steadily for at least $24 \mathrm{~h}$.

We, therefore, asked whether the data could be better represented on the basis of a three-compartment pharmacokinetic model (Fig. 4b) that includes, compared to the model used above (Fig. 4a), an extra compartment that we will refer to here as the "ocular tissues compartment" and which represents a compartment through which the drug transits when being drained from the vitreous into the systemic compartment. In this model, $\mathrm{k}_{2}$ represents the 


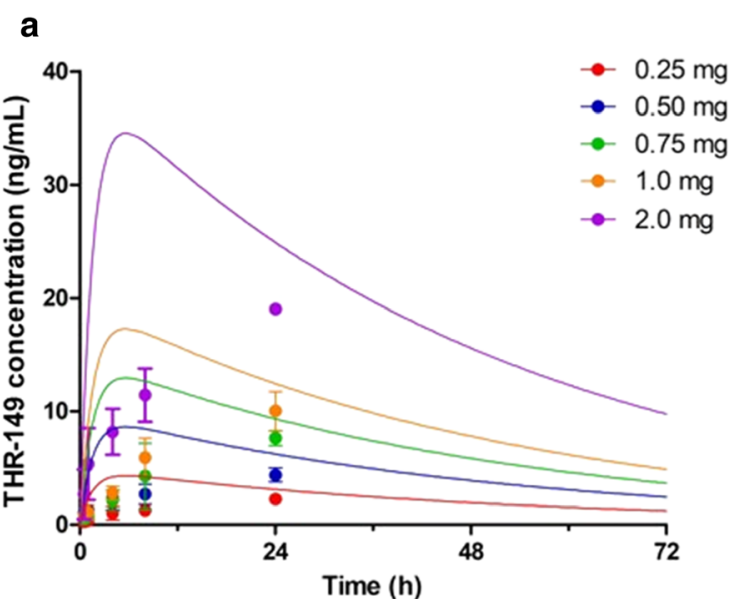

Fig. 5 Plasma levels following bilateral intravitreal administration of THR-149 in rabbit. Data are shown as mean \pm SD. Doses varied between 0.125 and $1 \mathrm{mg}$ per eye (corresponding to total doses per animal ranging from 0.25 to $2 \mathrm{mg}$ ). Data were analyzed based either (a) on a two-compartment pharmacokinetic model (Fig. 4a) using Eq. 7, or (b) on a three-compartment pharmacokinetic model

first-order rate constant for transfer of the drug from the ocular tissues compartment to the systemic compartment.

Similarly to Eq. syst. 1, the variation of the drug concentration in each compartment as a function of time can be obtained from the following system of linear differential equations (Eq. syst. 2) where A, B, and C represent the $\mathrm{VH}$, ocular tissues, and systemic compartments, respectively, and D the eliminated drug (Fig. 4b):

$$
\begin{aligned}
& d A / d t=-k_{1} \cdot A \\
& d B / d t=k_{1} \cdot A-k_{2} \cdot B \\
& d C / d t=k_{2} \cdot B-k_{3} \cdot C \\
& d D / d t=k_{3} \cdot C
\end{aligned}
$$

Solving/integrating this system of differential equations is, however, significantly more complex and the solutions have, to our knowledge, never been reported. We propose a methodology to tackle this problem in the 'Appendix' section of this manuscript which leads, after final re-arrangement, to the following analytical solution (Eqs. 8, 9, 10, 11):

$$
\begin{aligned}
A_{t}= & A_{0} \cdot e^{-k_{1} \cdot t} \\
B_{t}= & \frac{A_{0} \cdot k_{1}}{\left(k_{2}-k_{1}\right)} \cdot\left(e^{-k_{1} \cdot t}-e^{-k_{2} \cdot t}\right) \\
C_{t}= & \frac{A_{0} \cdot k_{1} \cdot k_{2}}{\left(k_{1}-k_{2}\right)} \cdot\left(\frac{1}{k_{1}-k_{3}} \cdot e^{-k_{1} \cdot t}+\frac{1}{k_{3}-k_{2}} \cdot e^{-k_{2} \cdot t}\right. \\
& \left.+\frac{k_{1}-k_{2}}{\left(k_{1}-k_{3}\right) \cdot\left(k_{2}-k_{3}\right)} \cdot e^{-k_{3} \cdot t}\right)
\end{aligned}
$$

b

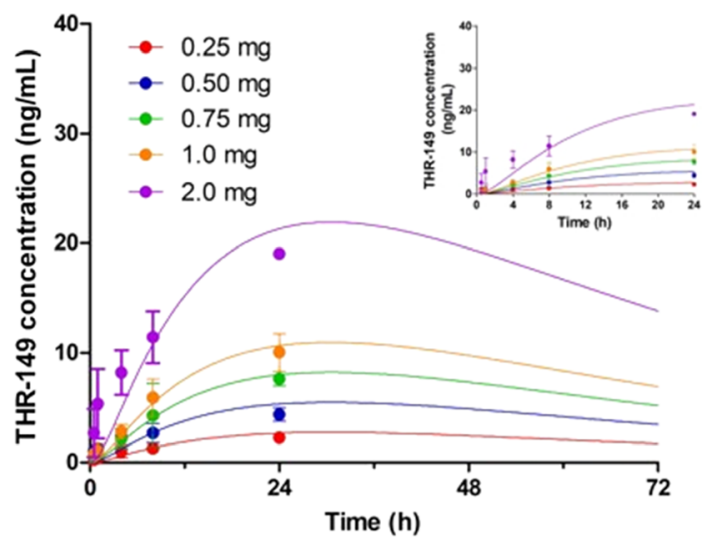

(Fig. 4b) using Eq. 13. The values of $\mathrm{k}_{1}$ and $\mathrm{k}_{3}$ in Eqs. 7 and 13 were fixed to those obtained from intravitreal and intravenous pharmacokinetics, respectively, i.e. $0.0195 \mathrm{~h}^{-1}$ and $0.64 \mathrm{~h}^{-1}$. The solid lines for (b) represent the best fit given by Eq. 13 with $\mathrm{k}_{2}$ set as the only variable parameter

$$
D_{t}=A_{0} \cdot\left(\begin{array}{l}
\frac{k_{2} \cdot k_{3}}{\left(k_{2}-k_{1}\right) \cdot\left(k_{1}-k_{3}\right)} \cdot e^{-k_{1} \cdot t}+\frac{k_{1} \cdot k_{3}}{\left(k_{1}-k_{2}\right) \cdot\left(k_{2}-k_{3}\right)} \cdot e^{-k_{2} \cdot t} \\
+\frac{k_{1} \cdot k_{2} \cdot\left(k_{2}-k_{1}\right)}{\left(k_{1}-k_{2}\right) \cdot\left(k_{1}-k_{3}\right) \cdot\left(k_{2}-k_{3}\right)} \cdot e^{-k_{3} \cdot t} \\
+\frac{k_{2} \cdot k_{3} \cdot\left(k_{2}-k_{3}\right)-k_{1} \cdot k_{3} \cdot\left(k_{1}-k_{3}\right)+k_{1} \cdot k_{2} \cdot\left(k_{1}-k_{2}\right)}{\left(k_{1}-k_{2}\right) \cdot\left(k_{1}-k_{3}\right) \cdot\left(k_{2}-k_{3}\right)}
\end{array}\right)
$$

In each compartment, the drug concentration depends on the dose and the volume of distribution of that compartment. Applying this reasoning to the two compartments that can be experimentally sampled, i.e. the $\mathrm{VH}$ and the systemic compartment (via collection of plasma), Eqs. 8 and 10 can be re-written into Eqs. 12 and 13 by substituting $\mathrm{D} / \mathrm{V}_{\mathrm{D}}$ for $\mathrm{A}_{0}$.

$$
\begin{aligned}
& {[\mathrm{THR}-149]_{V H}=\frac{D}{V_{D, V H}} \cdot e^{-k_{1} \cdot t}} \\
& {[\mathrm{THR}-149]_{s y s t}=\frac{D \cdot k_{1} \cdot k_{2}}{V_{D, s y s t} \cdot\left(k_{1}-k_{2}\right)}} \\
& \cdot\left(\frac{1}{k_{1}-k_{3}} \cdot e^{-k_{1} \cdot t}+\frac{1}{k_{3}-k_{2}} \cdot e^{-k_{2} \cdot t}+\frac{k_{1}-k_{2}}{\left(k_{1}-k_{3}\right) \cdot\left(k_{2}-k_{3}\right)} \cdot e^{-k_{3} \cdot t}\right)
\end{aligned}
$$

Following a similar reasoning as above, Eq. 13 can thus be used to model or analyze plasma concentration data following IVT administration. This equation, however, is relatively complex and robust determination of all individual parameters from a given set of experimental data may be challenging. Our approach was, therefore, to "educate" this model with the information obtained from intravitreal and intravenous pharmacokinetics, as illustrated in Fig. 6, by attributing a fixed value to the 


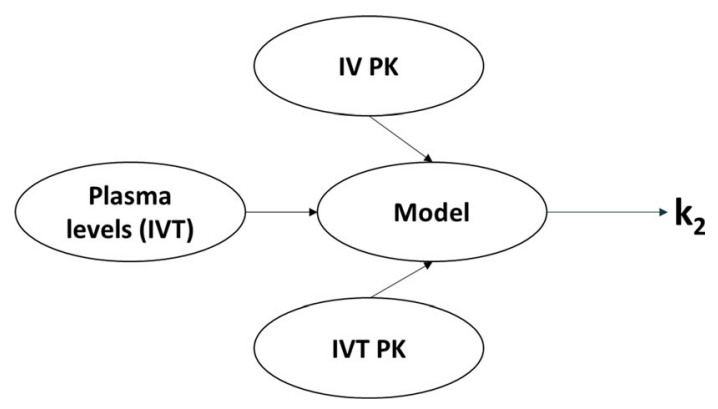

Fig. 6 General strategy for the analysis of drug plasma levels following intravitreal administration. The mathematical model (Eq. 13) is fed with data obtained from intravenous pharmacokinetics (IV PK) and intravitreal pharmacokinetics (IVT PK) by attributing fixed values to the parameters $\mathrm{D}, \mathrm{V}_{\mathrm{D} \text {,syst }}, \mathrm{k}_{1}$, and $\mathrm{k}_{3}$, leaving the sole $\mathrm{k}_{2}$ as a variable parameter

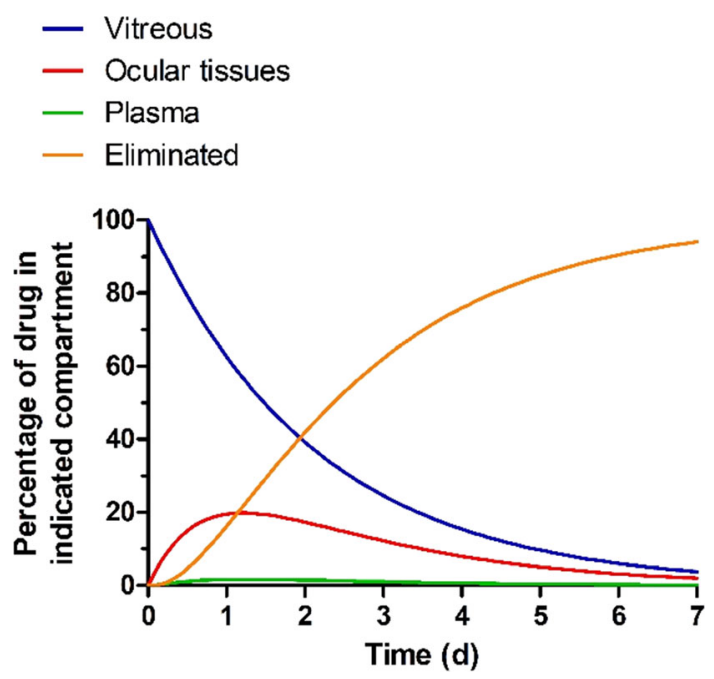

Fig. 7 Percentage of drug present in each of the compartments $(\mathrm{VH}$, ocular tissues, and systemic) and total percentage of drug eliminated following intravitreal administration of THR-149 in rabbit as predicted based on the pharmacokinetic model depicted in Fig. 4b. Calculations were based on Eqs. 8, 9, 10, 11 assuming the following values for the individual rate constants: $\mathrm{k}_{1}=0.0195 \mathrm{~h}^{-1}$; $\mathrm{k}_{2}=0.056 \mathrm{~h}^{-1} ; \mathrm{k}_{3}=0.64 \mathrm{~h}^{-1}$

parameters $\mathrm{V}_{\mathrm{D} \text {,syst }}, \mathrm{k}_{1}$, and $\mathrm{k}_{3}$, thus leaving $\mathrm{k}_{2}$ as the sole variable parameter. Analysis of experimental data with this methodology are shown in Fig. 5b. It is immediately apparent that Eq. 13 allows a much better prediction of the experimental data than Eq. 7 while remaining perfectly coherent with intravitreal and intravenous pharmacokinetic data. In addition, having "educated" Eq. 13 with intravitreal and intravenous pharmacokinetic data, the value for $\mathrm{k}_{2}$ can be extracted with very good precision (here $0.056 \mathrm{~h}^{-1}$ with a $95 \%$ confidence interval of $0.049-0.063$ - see also Table 1) despite the complexity of the model.

Finally, the analytical solution of Eq. syst. 2 in the form of Eqs. 8, 9, 10 and 11 allows to calculate the fraction or

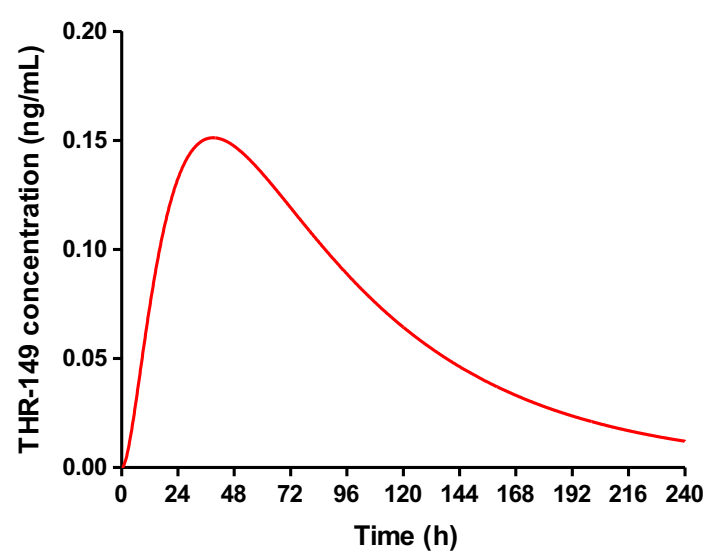

Fig. 8 Plasma levels following intravitreal administration of $125 \mu \mathrm{g}$ of THR-149 in human as predicted by the pharmacokinetic model shown in Fig. 4b and represented by Eq. 13. Parameters used for the calculations were as follows: body weight $=70 \mathrm{~kg}$; volume of distribution $=36 \mathrm{~L}(0.51 \mathrm{~L} / \mathrm{kg}) ; \mathrm{k}_{1}=0.014 \mathrm{~h}^{-1} ; \mathrm{k}_{2}=0.056 \mathrm{~h}^{-1}$; $\mathrm{k}_{3}=0.20 \mathrm{~h}^{-1}$

percentage of drug present in each of the compartments ( $\mathrm{VH}$, ocular tissues, and systemic) as well as the total fraction or percentage of drug eliminated by the organism at any moment in time (Fig. 7). These simulations suggest that the fraction of drug present in the ocular tissues compartment is highest $\sim 29 \mathrm{~h}$ post-administration, reaching $\sim 20 \%$ of the total administered dose. By contrast, the percentage of drug present in the systemic compartment is predicted to be low, remaining $<2 \%$ of the total administered drug at any point in time.

\section{Total systemic exposure following intravenous and intravitreal administration}

Total systemic exposure for intravenous or IVT administration, represented by the area under the curve (AUC) for the graph of plasma concentration vs. time, can be obtained by integrating Eq. 4 or Eq. 13 between 0 and $\propto$, which is straightforward for a sum of exponentials (Eq. 14).

$\int_{0}^{\infty} \sum_{i=1}^{i} A_{i} \cdot e^{-k_{i} \cdot t}=\sum_{i=1}^{i} \frac{A_{i}}{k_{i}}$

Noteworthy, but not surprisingly, integration of Eq. 13, i.e.

$$
\begin{aligned}
& \int_{0}^{\infty} \frac{D \cdot k_{1} \cdot k_{2}}{V_{D, \text { syst }} \cdot\left(k_{1}-k_{2}\right)} \\
& \cdot\left(\frac{1}{k_{1}-k_{3}} \cdot e^{-k_{1} \cdot t}+\frac{1}{k_{3}-k_{2}} \cdot e^{-k_{2} \cdot t}+\frac{k_{1}-k_{2}}{\left(k_{1}-k_{3}\right) \cdot\left(k_{2}-k_{3}\right)} \cdot e^{-k_{3} \cdot t}\right)
\end{aligned}
$$


leads to

$$
\begin{aligned}
A U C_{0-\infty} & =\frac{D \cdot k_{1} \cdot k_{2}}{V_{D, \text { syst }} \cdot\left(k_{1}-k_{2}\right)} \\
& \cdot\left(\frac{1}{k_{1} \cdot\left(k_{1}-k_{3}\right)}+\frac{1}{k_{2} \cdot\left(k_{3}-k_{2}\right)}+\frac{k_{1}-k_{2}}{k_{3} \cdot\left(k_{1}-k_{3}\right) \cdot\left(k_{2}-k_{3}\right)}\right)
\end{aligned}
$$

an expression which is identical to the solution obtained by integrating Eq. 4:

$$
\int_{0}^{\infty} \frac{D}{V_{D, s y s t}} \cdot e^{-k_{3} \cdot t}=\frac{D}{k_{3} \cdot V_{D, s y s t}}=\frac{D}{C L_{s y s t}}
$$

This demonstrates that total systemic exposure is independent of the route of administration and depends only on the dose, the systemic volume of distribution, and the rate constant of systemic elimination or, alternatively, on the dose and the systemic clearance.

\section{Extrapolation to human}

Proper interpretation of pharmacokinetic data in preclinical models is also essential to extrapolate or predict pharmacokinetics in human. Here, the predicted clearance of THR149 in the human VH can be determined using Eq. 18 (where the clearance is expressed in $\mathrm{mL} / \mathrm{h}$ ) which is based on the experimental comparison of the vitreal clearance in the rabbit and the human eye of a large number of compounds [25]. The vitreal volume of distribution of THR149 in the human eye can be determined assuming that the ratio between the volume of distribution and the volume of vitreous is the same in the rabbit and in the human eye (Eq. 19). Based on this and on Eq. 3, one can predict a value of $0.014 \mathrm{~h}^{-1}$ (corresponding to a half-life of $51 \mathrm{~h}$ ) for the rate of elimination of THR-149 in the human $\mathrm{VH}\left(\mathrm{k}_{1}\right.$ in model from Fig. 4b).

$$
\begin{aligned}
& C L_{\text {human }}=1.41 \cdot C L_{\text {rabbit }}+0.04 \\
& \frac{\text { Volume of distribution }(\text { human })}{\text { Vitreous volume }(\text { human })[4.36 \mathrm{~mL}]} \\
& \quad=\frac{\text { Volume of distribution }(\text { rabbit })[1.66 \mathrm{~mL}]}{\text { Vitreous volume }(\text { rabbit })[1.15 \mathrm{~mL}]}
\end{aligned}
$$

The rate of systemic elimination of THR-149 in human ( $\mathrm{k}_{3}$ in model from Fig. 4b) can be estimated assuming renal clearance at glomerular filtration rate $(120 \mathrm{~mL} / \mathrm{min}$ for a $70 \mathrm{~kg}$ individual) and a systemic volume of distribution identical to the one measured in the rabbit, i.e. $0.51 \mathrm{~L} / \mathrm{kg}$. Using Eq. 6 one can then calculate a value of $k_{3}$ of $0.20 \mathrm{~h}^{-1}$.

Based on the above numbers, it is thus possible to predict THR-149 plasma levels in human following IVT administration using Eq. 13. The only unknown is the value of the first-order rate constant for the elimination of the drug from the ocular tissues compartment $\left(\mathrm{k}_{2}\right.$ in model from Fig. 4b) in humans. Depending on the availability of specific information, it might be relevant to extrapolate the value of $\mathrm{k}_{2}$ in human based e.g. on the difference in trabecular mesh outflow or retinal blood flow between the two species. In the present case, though, there is no evidence that $\mathrm{k}_{2}$ represents aqueous humor $(\mathrm{AH})$-to-plasma transfer since AH-to-plasma transfer rate constants have been reported either for small molecules or biologics that are significantly larger than our value of $\mathrm{k}_{2}$ [17, 18]. Extrapolation of $\mathrm{k}_{2}$ to human based on trabecular mesh outflow thus doesn't seem appropriate. Similarly, since THR-149 elimination via the posterior route appears limited (see discussion section), extrapolation of $\mathrm{k}_{2}$ to human based on retinal blood flow seems equally inappropriate. In the absence of a solid rationale to extrapolate that rate constant from the data collected in rabbit, we thus chose to attribute the same value of $\mathrm{k}_{2}$ in the two species. Predicted plasma levels following monolateral IVT administration of $125 \mu \mathrm{g}$ of THR-149 (the highest dose tested in the clinic) are shown in Fig. 8. Plasma concentration is expected to reach a maximum value of only $0.15 \mathrm{ng} / \mathrm{mL} 39 \mathrm{~h}$ post-administration before decaying slowly. Predicted total systemic exposure is calculated to be $17.5(\mathrm{ng} / \mathrm{mL}) \mathrm{h}$ based on Eq. 16.

\section{Discussion}

Bicyclic peptides are constrained peptides consisting of a peptide sequence containing 3 cysteine residues which are covalently linked to a thiol-reactive molecular scaffold [26, 27]. With a molecular weight of $\sim 1.7 \mathrm{kDa}$, THR-149 thus lies between conventional small molecule drugs and macromolecules/biologics. At $0.032 \mathrm{~mL} / \mathrm{h}$, the vitreal clearance of THR-149 in the rabbit eye is relatively low, being at the very low end of the vitreal clearance spectrum observed for small molecules and at the higher end of the vitreal clearance spectrum observed for macromolecules, which may indicate dominant drug elimination via the anterior route and limited drug elimination via the posterior route (blood-retinal barrier) [25, 28]. The vitreal volume of distribution following IVT administration in rabbit was found to be well within the narrow range of $0.72-3.6 \mathrm{~mL}$ reported for a variety of molecules [25]. By contrast, with a half-life of only $1.1 \mathrm{~h}$, systemic elimination of THR-149 in the rabbit is fast. The volume of distribution $(0.51 \mathrm{~L} / \mathrm{kg})$ suggests distribution in total body water. Systemic clearance of THR-149 is $5.5 \mathrm{~mL} / \mathrm{min} / \mathrm{kg}$ which aligns with systemic pharmacokinetics in the rat (not shown) and is consistent with renal clearance [29].

Several approaches have been used to describe drug circulating levels following IVT administration. Some of 
the proposed models, however, are highly specific and/or elaborated and their complexity requires the use of specific software such as NONMEM (ICON Development Solutions, Dublin, Ireland) or SimBiology (MathWorks, Inc., Natick, MA, USA). Therefore, by its simplicity, a twocompartment model such as proposed by $\mathrm{Xu}$ et al. and Zhang et al. [20, 21] (Fig. 4a) may arguably appear as the most generally applicable. This model, however, proved inadequate to describe THR-149 circulating levels following IVT administration in the rabbit. By contrast, experimental data could be accurately represented on the basis of a three-compartment model that assumes the existence of an additional compartment localized between the VH compartment and the systemic compartment (Fig. 4b). Here, we have referred to the additional compartment as the "ocular tissues" compartment. Worth noting, however, and because of the very nature of compartmental pharmacokinetic modelling, we cannot speculate as to where the drug exactly physically distributes in that compartment; hence the model only provides information on the drug distribution between the different compartments over time as well as on the rates of drug transfer from one compartment to the next.

Intuitively, because the vitreous is not in direct physical contact with the plasma, the need to consider the existence of an ocular tissues compartment to accurately describe the evolution of plasma levels following IVT administration is not incongruous. In addition, we report in our accompanying paper a similar observation in the rabbit and the pig for THR-687, a pan-integrin antagonist currently in development for the treatment of diabetic macular edema. $\mathrm{We}$, therefore, hypothesize that the reasoning used here applies to a majority of drugs administered intravitreally and that circulating levels could be analyzed with the model proposed here, at least for drugs which systemic elimination obeys mono-compartmental pharmacokinetics (for drugs which systemic elimination obeys bi-compartmental pharmacokinetics, we refer the reader to our accompanying paper).

Another significant advantage of the methodology depicted here lies in the fact that we provide an analytical solution to the system of linear differential equations that describes the proposed model, which eliminates the need for complex software's such as those mentioned above and allows data analysis by standard nonlinear regression analysis. Of note, it is conceivable that data analysis using Eq. 13 would return a value of $k_{2}$ much larger than the one of $\mathrm{k}_{1}$. This, however, would not invalidate the general concept proposed here but rather simply indicate that the tested drug doesn't accumulate significantly in the ocular tissues compartment. To be observed, Eq. 13 simplifies into Eq. 7 when $\mathrm{k}_{2} \gg \mathrm{k}_{1} \& \mathrm{k}_{3}$.
Although accurately describing THR-149 circulating levels following intravitreal administration, it is, however, necessary to mention that one aspect that the proposed model does not incorporate is binding to the drug target. Drug-target interaction can potentially modify the overall drug elimination and other researchers have very elegantly addressed the matter (see e.g. [16, 17]). However, the impact of target binding on overall drug elimination can only become significant when the drug levels and the target concentration are of the same order of magnitude. Given that intravitreal administration results in high drug levels in the vitreous chamber [2], it is likely that in a majority of cases the drug concentration will be much larger than the target concentration, making it possible to neglect drugtarget interaction in pharmacokinetic modelling.

Also, rather than the empirical approach used here which assumes the existence of a unique and undefined ocular tissues compartment, other pharmacokinetic models have been proposed that incorporate more physiological/morphological aspects of drug ocular elimination and distribution. E.g. Gadkar et al., (2015), Le et al., (2015), and Luu et al., (2020) have reported sophisticated models that account for drug distribution within the retina (or retina and choroid) and diffusion to the aqueous humor $[16,17,19]$, and Buitrago et al. have applied a model which allows the drug to reach the circulation both from the vitreous and from the aqueous humor, thereby accounting for anterior and posterior ocular clearance [18]. However, given the differences in structure and assumptions made between our proposition and these different models, additional studies applied to various types of drugs will be necessary to compare these models for their ability to accurately predict drug circulating levels following ocular administration.

\section{Conclusion}

We describe, here and in our accompanying paper, pharmacokinetic models for the analysis and prediction of plasma levels following IVT administration and hypothesize that these models will apply to a variety of drugs administered in the eye.

\section{Appendix}

We propose the following methodology to solve/integrate Eq. syst. A. 


$$
\begin{aligned}
& d A / d t=-k_{1} \cdot A \\
& d B / d t=k_{1} \cdot A-k_{2} \cdot B \\
& d C / d t=k_{2} \cdot B-k_{3} \cdot C \\
& d D / d t=k_{3} \cdot C
\end{aligned}
$$

The first step is to re-arrange the system of differential equations in the form of Eq. A:

$$
\left(\begin{array}{l}
d A / d t \\
d B / d t \\
d C / d t \\
d D / d t
\end{array}\right)=\left(\begin{array}{cccc}
-k_{1} & 0 & 0 & 0 \\
k_{1} & -k_{2} & 0 & 0 \\
0 & k_{2} & -k_{3} & 0 \\
0 & 0 & k_{3} & 0
\end{array}\right)\left(\begin{array}{l}
A \\
B \\
C \\
D
\end{array}\right)
$$

Let's call it the primary system and let's call $X$ the column vector of the unknowns.

$X=\left(\begin{array}{c}A \\ B \\ C \\ D\end{array}\right)$

and

$\dot{X}=\left(\begin{array}{l}d A / d t \\ d B / d t \\ d C / d t \\ d D / d t\end{array}\right)$

its temporal derivative. Let's also call

$S=\left(\begin{array}{cccc}-k_{1} & 0 & 0 & 0 \\ k_{1} & -k_{2} & 0 & 0 \\ 0 & k_{2} & -k_{3} & 0 \\ 0 & 0 & k_{3} & 0\end{array}\right)$

the primary system matrix. The primary system of differential equations can then be written in matrix form:

$\dot{X}=S \cdot X$

The four differential equations of the primary system (Eq. syst. A) are coupled. This means that the derivative of one unknown depends on one or several other unknowns. For example, $\mathrm{dB} / \mathrm{dt}$ depends on $\mathrm{B}$ with the coefficient $-\mathrm{k}_{2}$ but also on $\mathrm{A}$ with the coefficient $\mathrm{k}_{1}$. The reasoning here is to de-couple the four equations so that the derivative of each unknown only depends on itself. The mathematical technique we used is the diagonalization of the matrix S so that we can write:

$S=P D P^{-1}$

where $\mathrm{D}$ is a diagonal matrix containing the eigenvalues of the matrix S, i.e.:
$D=\left(\begin{array}{cccc}\lambda_{1} & 0 & 0 & 0 \\ 0 & \lambda_{2} & 0 & 0 \\ 0 & 0 & \lambda_{3} & 0 \\ 0 & 0 & 0 & \lambda_{4}\end{array}\right)$

and $\mathrm{P}$ is a squared matrix where the columns are the eigenvectors of $S$ corresponding to the eigenvalues $\lambda_{1}, \lambda_{2}$, $\lambda_{3}$, and $\lambda_{4}$, in the same order. $\mathrm{P}^{-1}$ is the inverse matrix of $\mathrm{P}$. The eigenvalues of the matrix $S$ are the four solutions (roots) of the characteristic equation of $\mathrm{S}$ :

$\operatorname{dtm}(S-\lambda I)=0$

where dtm is the determinant of the matrix and $\mathrm{I}$ the identity matrix. Here, $\lambda_{1}=-\mathrm{k}_{1}, \lambda_{2}=-\mathrm{k}_{2}, \lambda_{3}=-\mathrm{k}_{3}$, and $\lambda_{4}=0$ so that

$D=\left(\begin{array}{cccc}-\mathrm{k}_{1} & 0 & 0 & 0 \\ 0 & -\mathrm{k}_{2} & 0 & 0 \\ 0 & 0 & -\mathrm{k}_{3} & 0 \\ 0 & 0 & 0 & 0\end{array}\right)$

The eigenvectors $v_{i}$ associated to each eigenvalue $\lambda_{i}$ $(i=1,2,3,4)$ are the solutions of the system

$S v_{i}=\lambda_{i} v_{i}(i=1,2,3,4)$

In our context, this leads to:

$$
\begin{aligned}
v_{1}= & \left(\begin{array}{c}
-\left(k_{1}-k_{2}\right)\left(k_{1}-k_{3}\right) /\left(k_{2} k_{3}\right) \\
k_{1}\left(k_{1}-k_{3}\right) /\left(k_{2} k_{3}\right) \\
-k_{1} / k_{3} \\
1
\end{array}\right), v_{2} \\
= & \left(\begin{array}{c}
0 \\
0 \\
\left.k_{2}-k_{3}\right) / k_{3} \\
-k_{2} / k_{3} \\
1
\end{array}\right), v_{3}=\left(\begin{array}{c}
0 \\
0 \\
-1 \\
1
\end{array}\right), v_{4}=\left(\begin{array}{l}
0 \\
0 \\
0 \\
1
\end{array}\right)
\end{aligned}
$$

so that

$P=\left(\begin{array}{cccc}-\left(k_{1}-k_{2}\right)\left(k_{1}-k_{3}\right) /\left(k_{2} k_{3}\right) & 0 & 0 & 0 \\ k_{1}\left(k_{1}-k_{3}\right) /\left(k_{2} k_{3}\right) & \left(k_{2}-k_{3}\right) / k_{3} & 0 & 0 \\ -k_{1} / k_{3} & -k_{2} / k_{3} & -1 & 0 \\ 1 & 1 & 1 & 1\end{array}\right)$

To be noted, $\mathrm{P}$ only exists if $\mathrm{k}_{2} \cdot \mathrm{k}_{3} \neq 0$ and $\mathrm{P}^{-1}$ only exists if $\mathrm{k}_{1} \neq \mathrm{k}_{2}, \mathrm{k}_{1} \neq \mathrm{k}_{3}$, and $\mathrm{k}_{2} \neq \mathrm{k}_{3}$. If $\mathrm{k}_{1}=\mathrm{k}_{2}$ and/or $\mathrm{k}_{1}=\mathrm{k}_{3}$ and/or $\mathrm{k}_{2}=\mathrm{k}_{3}$, the matrix $\mathrm{S}$ is not diagonalizable and the methodology described here is not applicable.

Including Eq. F into Eq. E leads to

$\dot{X}=P D P^{-1} X$

Multiplying the two sides of this last equality by $\mathrm{P}^{-1}$ leads to: 
$P^{-1} \dot{X}=P^{-1} P D P^{-1} X \leftrightarrow\left(P^{-1} X\right)=D\left(P^{-1} X\right) \leftrightarrow \dot{Y}=D Y$

where $\left(P^{-1} X\right)$ is equal to $\left(P^{-1} \dot{X}\right)$ since $\mathrm{P}^{-1}$ is a constant matrix and where we introduced

$Y=P^{-1} X=\left(\begin{array}{l}A^{\prime} \\ B^{\prime} \\ C^{\prime} \\ D^{\prime}\end{array}\right)$

Here, $\mathrm{A}^{\prime}, \mathrm{B}^{\prime}, \mathrm{C}^{\prime}$, and $\mathrm{D}^{\prime}$ are the four secondary unknowns from which one can deduce the four primary unknowns $\mathrm{A}, \mathrm{B}, \mathrm{C}$, and $\mathrm{D}$ using

$$
\left(\begin{array}{l}
A \\
B \\
C \\
D
\end{array}\right)=X=P Y=P\left(\begin{array}{l}
A^{\prime} \\
B^{\prime} \\
C^{\prime} \\
D^{\prime}
\end{array}\right)
$$

The secondary system of differential equations

$$
\dot{Y}=D Y
$$

which can also be written

$$
\left(\begin{array}{l}
d A^{\prime} / d t \\
d B^{\prime} / d t \\
d C^{\prime} / d t \\
d D^{\prime} / d t
\end{array}\right)=\left(\begin{array}{cccc}
\lambda_{1} & 0 & 0 & 0 \\
0 & \lambda_{2} & 0 & 0 \\
0 & 0 & \lambda_{3} & 0 \\
0 & 0 & 0 & \lambda_{4}
\end{array}\right)\left(\begin{array}{l}
A^{\prime} \\
B^{\prime} \\
C^{\prime} \\
D^{\prime}
\end{array}\right)
$$

is now de-coupled and each of the four secondary differential equations can be solved/integrated separately with:

$$
\begin{gathered}
A^{\prime}=C_{1} \cdot e^{\lambda_{1} \cdot t}=C_{1} \cdot e^{-k_{1} \cdot t} \\
B^{\prime}=C_{2} \cdot e^{\lambda_{2} \cdot t}=C_{2} \cdot e^{-k_{2} \cdot t} \\
C^{\prime}=C_{3} \cdot e^{\lambda_{3} \cdot t}=C_{3} \cdot e^{-k_{3} \cdot t} \\
D^{\prime}=C_{4} \cdot e^{\lambda_{4} \cdot t}=C_{4}
\end{gathered}
$$

where $\mathrm{C}_{1}, \mathrm{C}_{2}, \mathrm{C}_{3}$, and $\mathrm{C}_{4}$ are constants that will be fixed based on the initial conditions of the primary system. Introducing $\mathrm{A}^{\prime}, \mathrm{B}^{\prime}, \mathrm{C}^{\prime}$, and $\mathrm{D}^{\prime}$ in Eq. $\mathrm{P}$ and using Eq. $\mathrm{L}$ of matrix $\mathrm{P}$ leads to:

$$
\begin{aligned}
& \left(\begin{array}{l}
A \\
B \\
C \\
D
\end{array}\right)=\left(\begin{array}{cccc}
-\left(k_{1}-k_{2}\right)\left(k_{1}-k_{3}\right) /\left(k_{2} k_{3}\right) & 0 & 0 & 0 \\
k_{1}\left(k_{1}-k_{3}\right) /\left(k_{2} k_{3}\right) & \left(k_{2}-k_{3}\right) / k_{3} & 0 & 0 \\
-k_{1} / k_{3} & -k_{2} / k_{3} & -1 & 0 \\
1 & 1 & 1 & 1
\end{array}\right) \\
& \left(\begin{array}{c}
C_{1} \cdot e^{-k_{1} \cdot t} \\
C_{2} \cdot e^{-k_{2} \cdot t} \\
C_{3} \cdot e^{-k_{3} \cdot t} \\
C_{4}
\end{array}\right)
\end{aligned}
$$

or

$$
\begin{aligned}
& A_{t}=-C_{1} \cdot \frac{\left(k_{1}-k_{2}\right)\left(k_{1}-k_{3}\right)}{k_{2} k_{3}} \cdot e^{-k_{1} \cdot t} \\
& B_{t}=C_{1} \cdot \frac{k_{1}\left(k_{1}-k_{3}\right)}{k_{2} k_{3}} \cdot e^{-k_{1} \cdot t}+C_{2} \cdot \frac{k_{2}-k_{3}}{k_{3}} \cdot e^{-k_{2} \cdot t} \\
& C_{t}=-C_{1} \cdot \frac{k_{1}}{k_{3}} \cdot e^{-k_{1} \cdot t}-C_{2} \cdot \frac{k_{2}}{k_{3}} \cdot e^{-k_{2} \cdot t}-C_{3} \cdot e^{-k_{3} \cdot t} \\
& D_{t}=C_{1} \cdot e^{-k_{1} \cdot t}+C_{2} \cdot e^{-k_{2} \cdot t}+C_{3} \cdot e^{-k_{3} \cdot t}+C_{4}
\end{aligned}
$$

(syst.C)

Using as initial conditions $A_{t=0}=A_{0}, B_{t=0}=0, C_{t=0}$ $=0$, and $\mathrm{D}_{\mathrm{t}=0}=0$ leads to a linear system of four equations in the four scalar unknowns $\mathrm{C}_{1}, \mathrm{C}_{2}, \mathrm{C}_{3}$, and $\mathrm{C}_{4}$ the resolution of which leads to:

$$
\begin{aligned}
& C_{1}=A_{0} \cdot \frac{k_{2} \cdot k_{3}}{\left(k_{2}-k_{1}\right) \cdot\left(k_{1}-k_{3}\right)} \\
& C_{2}=A_{0} \cdot \frac{k_{1} \cdot k_{3}}{\left(k_{1}-k_{2}\right) \cdot\left(k_{2}-k_{3}\right)} \\
& C_{3}=A_{0} \cdot \frac{k_{1} \cdot k_{2} \cdot\left(k_{2}-k_{1}\right)}{\left(k_{1}-k_{2}\right) \cdot\left(k_{1}-k_{3}\right) \cdot\left(k_{2}-k_{3}\right)} \\
& C_{4}=A_{0} \cdot \frac{k_{2} \cdot k_{3} \cdot\left(k_{2}-k_{3}\right)-k_{1} \cdot k_{3} \cdot\left(k_{1}-k_{3}\right)+k_{1} \cdot k_{2} \cdot\left(k_{1}-k_{2}\right)}{\left(k_{1}-k_{2}\right) \cdot\left(k_{1}-k_{3}\right) \cdot\left(k_{2}-k_{3}\right)}
\end{aligned}
$$

Finally, introducing Eqs. T, U, V and W into Eq. syst. C and re-arranging leads to Eqs. 8, 9, 10 and 11 above.

Acknowledgements The authors wish to thank Astrid De Vriese, Nele Leenders and Sofie Molenberghs (Oxurion N.V.) for excellent technical assistance, and Dr Jean H. M. Feyen for constant support.

Author contributions Experimental design \& generation of experimental data [BN, TVB]; Conceptualization [MV]; Mathematical developments [MV, J-MW]; Data analysis \& interpretation [MV]; Resources management [PB]; Writing of original draft manuscript [MV]; Final review and editing of manuscript [PB, AS].

\section{Declarations}

Conflict of interest Jean-Marc Wagner has no financial or non-financial interests to disclose. Marc Vanhove, Bernard Noppen, Tine Van Bergen, and Philippe Barbeaux are employees of Oxurion N.V. Alan Stitt is consultant to Oxurion N.V.

Open Access This article is licensed under a Creative Commons Attribution 4.0 International License, which permits use, sharing, adaptation, distribution and reproduction in any medium or format, as long as you give appropriate credit to the original author(s) and the source, provide a link to the Creative Commons licence, and indicate if changes were made. The images or other third party material in this article are included in the article's Creative Commons licence, unless indicated otherwise in a credit line to the material. If material is not included in the article's Creative Commons licence and your intended use is not permitted by statutory regulation or exceeds the permitted use, you will need to obtain permission directly from the copyright holder. To view a copy of this licence, visit http://creativecommons. org/licenses/by/4.0/. 


\section{References}

1. Storey PP, Pancholy M, Wibbelsman TD, Obeid A, Su D, Borkar D, Garg S, Gupta O (2019) Rhegmatogenous retinal detachment after intravitreal injection of anti-vascular endothelial growth factor. Ophthalmology 126:1424-1431

2. Varela-Fernández R, Díaz-Tomé V, Luaces-Rodríguez A, CondePenedo A, García-Otero X, Luzardo-Álvarez A, Fernández-Ferreiro A, Otero-Espinar FJ (2020) Drug delivery to the posterior segment of the eye: biopharmaceutic and pharmacokinetic considerations. Pharmaceutics 12:269. https://doi.org/10.3390/ pharmaceutics12030269

3. Falavarjani KG, Nguyen QD (2013) Adverse events and complications associated with intravitreal injection of anti-VEGF agents: a review of literature. Eye (Lond) 27:787-794

4. Chakravarthy U, Harding SP, Rogers CA, Downes SM, Lotery AJ, Culliford LA, Reeves BC, IVAN study investigators (2013) Alternative treatments to inhibit VEGF in age-related choroidal neovascularisation: 2-year findings of the IVAN randomised controlled trial. Lancet 382:1258-1267

5. Cruess AF, Giacomantonio N (2014) Cardiac issues of noncardiac drugs: the rising story of avastin in age-related macular degeneration. Ophthalmologica 231:75-79

6. Hanna RM, Barsoum M, Arman F, Selamet U, Hasnain H, Kurtz I (2019) Nephrotoxicity induced by intravitreal vascular endothelial growth factor inhibitors: emerging evidence. Kidney Int 96:572-580

7. Cutroneo PM, Giardina C, Ientile V, Potenza S, Sottosanti L, Ferrajolo C, Trombetta CJ, Trifirò G (2017) Overview of the safety of anti-VEGF drugs: analysis of the Italian spontaneous reporting system. Drug Saf 40:1131-1140

8. Gaudreault J, Fei D, Beyer JC, Ryan A, Rangell L, Shiu V, Damico LA (2007) Pharmacokinetics and retinal distribution of ranibizumab, a humanized antibody fragment directed against VEGF-A, following intravitreal administration in rabbits. Retina 27:1260-1266

9. Nomoto H, Shiraga F, Kuno N, Kimura E, Fujii S, Shinomiya K, Nugent AK, Hirooka K, Baba T (2009) Pharmacokinetics of bevacizumab after topical, subconjunctival, and intravitreal administration in rabbits. Invest Ophthalmol Vis Sci 50:4807-4813

10. Christoforidis JB, Briley K, Binzel K, Bhatia P, Wei L, Kumar K, Knopp MV (2017) Systemic biodistribution and intravitreal pharmacokinetic properties of bevacizumab, ranibizumab, and aflibercept in a nonhuman primate model. Invest Ophthalmol Vis Sci 58:5636-5645

11. Bantseev V, Erickson R, Leipold D, Amaya C, Miller PE, Booler H, Thackaberry EA (2018) Nonclinical safety assessment of antiFactor D: key strategies and challenges for the nonclinical development of intravitreal biologics. J Ocul Pharmacol Ther 34:204-213

12. Avery RL, Castellarin AA, Steinle NC, Dhoot DS, Pieramici DJ, See R, Couvillion S, Nasir MA, Rabena MD, Le K, Maia M, Visich JE (2014) Systemic pharmacokinetics following intravitreal injections of ranibizumab, bevacizumab or aflibercept in patients with neovascular AMD. Br J Ophthalmol 98:1636-1641

13. Kong L, Bhatt AR, Demny AB, Coats DK, Li A, Rahman EZ, Smith OE, Steinkuller PG (2015) Pharmacokinetics of bevacizumab and its effects on serum VEGF and IGF-1 in infants with retinopathy of prematurity. Invest Ophthalmol Vis Sci 56:956-961

14. Avery RL, Castellarin AA, Steinle NC, Dhoot DS, Pieramici DJ, See R, Couvillion S, Nasir MA, Rabena MD, Maia M, Van Everen S, Le K, Hanley WD (2017) Systemic pharmacokinetics and pharmacodynamics of intravitreal aflibercept, bevacizumab, and ranibizumab. Retina 37:1847-1858

15. Kaiser PK, Kodjikian L, Korobelnik JF, Winkler J, Torri A, Zeitz O, Vitti R, Ahlers C, Zimmermann T, Dicioccio AT, Höchel J
(2019) Systemic pharmacokinetic/pharmacodynamic analysis of intravitreal aflibercept injection in patients with retinal diseases. BMJ Open Ophthalmol 4(1):e000185

16. Le KN, Gibiansky L, Good J, Davancaze T, van Lookeren CM, Loye KM, Morimoto A, Jin J, Damico-Beyer LA, Hanley WD (2015) A mechanistic pharmacokinetic/pharmacodynamic model of factor $\mathrm{D}$ inhibition in cynomolgus monkeys by lampalizumab for the treatment of geographic atrophy. J Pharmacol Exp Ther 355:288-296

17. Luu KT, Seal JR, Attar M (2020) A mechanistic and translational pharmacokinetic-pharmacodynamic model of abicipar pegol and vascular endothelial growth factor Inhibition. J Pharmacol Exp Ther 373:184-192

18. Buitrago E, Höcht C, Chantada G, Fandiño A, Navo E, Abramson DH, Schaiquevich P, Bramuglia GF (2010) Pharmacokinetic analysis of topotecan after intra-vitreal injection. Implications for retinoblastoma treatment. Exp Eye Res 91:9-14

19. Gadkar K, Pastuskovas CV, Le Couter JE, Elliott JM, Zhang J, Lee CV, Sanowar S, Fuh G, Kim HS, Lombana TN, Spiess C, Nakamura M, Hass P, Shatz W, Meng YG, Scheer JM (2015) Design and pharmacokinetic characterization of novel antibody formats for ocular therapeutics. Invest Ophthalmol Vis Sci $56: 5390-5400$

20. Xu L, Lu T, Tuomi L, Jumbe N, Lu J, Eppler S, Kuebler P, Damico-Beyer LA, Joshi A (2013) Pharmacokinetics of ranibizumab in patients with neovascular age-related macular degeneration: a population approach. Invest Ophthalmol Vis Sci 54:1616-1624

21. Zhang Y, Yao Z, Kaila N, Kuebler P, Visich J, Maia M, Tuomi L, Ehrlich JS, Rubio RG, Campochiaro PA (2014) Pharmacokinetics of ranibizumab after intravitreal administration in patients with retinal vein occlusion or diabetic macular edema. Ophthalmology 121:2237-2246

22. Teufel DP, Bennett G, Harrison H, Van Rietschoten K, Pavan S, Stace C, Le Floch F, Van Bergen T, Vermassen E, Barbeaux P, Hu T-T, Feyen JHM, Vanhove M (2018) Stable and long-lasting, novel bicyclic peptide plasma kallikrein inhibitors for the treatment of diabetic macular edema. J Med Chem 61:2823-2836

23. Aerts F, Noppen B, Fonteyn L, Derua R, Waelkens E, de Sme MD, Vanhove M (2012) Mechanism of inactivation of ocriplasmin in porcine vitreous. Biophys Chem 165-166:30-38

24. Swain CG (1944) The kinetic analysis of consecutive irreversible first order reactions. J Am Chem Soc 10:1696-1700

25. del Amo EM, Vellonen K-S, Kidron H, Urtti A (2015) Intravitreal clearance and volume of distribution of compounds in rabbits: in silico prediction and pharmacokinetic simulations for drug development. Eur J Pharm Biopharm 95:215-226

26. Rhodes CA, Dehua P (2017) Bicyclic peptides as next-generation therapeutics. Chemistry 23:12690-12703

27. Heinis C, Rutherford T, Freund S, Winter G (2009) Phage-encoded combinatorial chemical libraries based on bicyclic peptides. Nat Chem Biol 5:502-507

28. del Amo EM, Rimpelä A-K, Heikkinen E, Kari OK, Ramsay E, Lajunen T, Schmitt M, Pelkonen L, Bhattacharya M, Richardson D, Subrizi A, Turunen T, Reinisalo M, Itkonen J, Toropainen E, Casteleijn M, Kidron H, Antopolsky M, Vellonen K-S, Ruponen M, Urtti A (2017) Pharmacokinetic aspects of retinal drug delivery. Prog Retin Eye Res 57:134-185

29. Lippi I, Perondi F, Petrini D, La Fortuna MC, Luci G, Intorre L, Guidi G, Meucci V (2019) Evaluation of glomerular filtration rate estimation by means of plasma clearance of iohexol in domestic rabbits (Oryctolagus cuniculus). Am J Vet Res 80:525-532

Publisher's Note Springer Nature remains neutral with regard to jurisdictional claims in published maps and institutional affiliations. 